\title{
Amiodarone-induced thyroid dysfunction
}

\author{
Ian Louis Ross, David Marshall, Andrzej Okreglicki, Sedick Isaacs \& Naomi \\ Sharlene Levitt
}

To cite this article: Ian Louis Ross, David Marshall, Andrzej Okreglicki, Sedick Isaacs \& Naomi Sharlene Levitt (2005) Amiodarone-induced thyroid dysfunction, Journal of Endocrinology, Metabolism and Diabetes of South Africa, 10:1, 6-9, DOI: 10.1080/22201009.2005.10872108

To link to this article: https://doi.org/10.1080/22201009.2005.10872108

\section{(c) 2005 SEMDSA. Published by Medpharm.}

曲 Published online: 12 Aug 2014.

Submit your article to this journal

Џ Article views: 82

Q View related articles $₫$ 


\title{
ARTICLE \\ Amiodarone-induced thyroid dysfunction
}

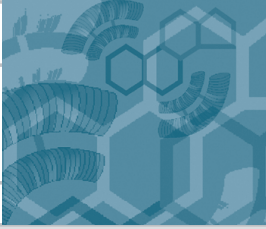

\author{
Divisions of Endocrinology and Cardiology and Medical Informatics, Groote Schuur Hospital \\ and University of Cape Town \\ Ian Louis Ross, MB ChB, FCP (SA), Cert Endocrinology and Metabolism (SA) \\ David Marshall, MB ChB, FCP (SA) \\ Andrzej Okreglicki, MB ChB, FCP (SA) \\ Sedick Isaacs, $\mathrm{PhD}$ \\ Naomi Sharlene Levitt, MB ChB, MD
}

Background. Little is known about the frequency of thyroid dysfunction (TD) associated with amiodarone therapy in southern Africa.

Objectives. To determine the incidence of TD in a cohort of patients initiated on amiodarone therapy at a cardiac clinic in Cape Town, South Africa, believed to be an iodine-replete area.

Patients. Pharmacy records were used to obtain the names of patients who received amiodarone between November 1999 and December 2002

Results. The sample size was 194, but data analysis was limited to the 163 patients for whom there were complete data. The mean age \pm standard deviation (SD) was $59.0 \pm 15.0$ years (range 22 - 89 years). There were 67 female and 96 male patients. The indications for amiodarone therapy were supraventricular tachycardias $(N=102,62.6 \%)$, ventricular tachycardia $(N=55,33.7 \%)$, and prophylaxis against tachycardias $(N=3,1.8 \%)$. The indication was uncertain in 3 patients (1.8\%). The median duration of amiodarone treatment was 679.0 days (quartile deviation (OD) 1172 days, range $3-6425$ days) in the whole cohort. The median duration of amiodarone therapy until new TD was 943 days (OD 1185 days), significantly longer than in patients who remained euthyroid (547 days, OD 1135 days) $(P=0.05)$. There were 45 new TD cases $(27.6 \%)$ : 11 patients $(6.7 \%)$ were thyrotoxic, $1(0.6 \%)$ transient thyrotoxicosis, 1 (0.6\%) subclinical hyperthyroidism, 13 (8.0\%) had subclinical hypothyroidism, 12 (7.4\%) hypothyroidism and 7 (4.3\%) had minor changes in thyroid function.

Conclusions. We found a high incidence of new-onset TD, similar to the highest rates reported internationally. Local factors responsible for this need to be investigated.

S Afr Med J 2005; 95: 180-183

Amiodarone is a widely used anti-arrhythmic drug with considerable potential to cause thyroid dysfunction (TD) because of its 35\% iodine content. ${ }^{1}$ Indeed, each $200 \mathrm{mg}$ tablet (the usual daily maintenance dose) contains $75 \mathrm{mg}$ of organic iodide with approximately $7.5 \mathrm{mg}$ free iodide being released daily. This greatly exceeds the daily dietary iodine requirement of $0.2-0.8 \mathrm{mg}^{2}$

The frequency of reported TD with amiodarone therapy has ranged from $2 \%$ to $24 \%{ }^{3}$ It is generally accepted that the frequency of hypothyroidism and hyperthyroidism is accounted for by differing levels of iodine intake. Hyperthyroidism is therefore most likely to occur in patients from areas with low environmental iodine in contrast to hypothyroidism where patients hail from iodine-replete or excess areas. The mechanism of amiodarone-induced hypothyroidism may be mediated by excess iodide. The large amount of iodide released by metabolism of amiodarone inhibits thyroid hormone biosynthesis (the Wolff-Chaikoff effect). Escape from the Wolff-Chaikoff effect usually occurs, yet there is persistence of the hypothyroid state in patients with amiodarone-induced hypothyroidism. This is attributed to a subtle defect in thyroid hormonogenesis that results in enhanced susceptibility to the inhibitory effect of iodine on hormone synthesis. ${ }^{4,5} \mathrm{~A}$ disturbance of intrinsic thyroid iodine autoregulation is thought to account for amiodarone-induced thyrotoxicosis, but these mechanisms are incompletely understood. 2,4,6,7

Hyperthyroid states associated with amiodarone have traditionally been categorised into two main classes. Type 1 refers to patients with an underlying thyroid disorder such as multinodular disease or Graves' disease, who on exposure to an excessive amount of iodine develop thyrotoxicosis. Type 2 hyperthyroidism is characterised by an absence of either Graves' disease or multinodular disease, but the thyroid is vulnerable to inflammatory attack. 8,9

In addition to the abovementioned forms of TD, amiodarone may also induce minor derangements of thyroid function tests. These are not clinically significant, should be recognised as the effect of amiodarone, and do 
not require any specific therapy. Amiodarone is a potent inhibitor of type 1 and type 2 5'-deiodinase of thyroxine, the enzymes that convert $\mathrm{T}_{4}$ to $\mathrm{T}_{3}$. This inhibition may result in an elevated thyroid-stimulating hormone (TSH) level, together with a mildly elevated or normal $\mathrm{T}_{4}$ and a low $\mathrm{T}_{3}$ level. ${ }^{10}$ In addition, amiodarone affects pituitary release of TSH and may therefore cause the inappropriate TSH syndrome. ${ }^{3,4,10}$

Little is known about the frequency of TD related to amiodarone use in southern Africa, as the reported studies emanate from Europe and the USA. We therefore examined the incidence of TD in a cohort of patients started on amiodarone therapy at the cardiac clinic, Groote Schuur Hospital in Cape Town. Groote Schuur Hospital is the teaching hospital of the University of Cape Town and is a referral centre for patients with cardiac arrythmias resident in Cape Town and surrounding areas. As Cape Town is believed to be an iodine-replete area, it was assumed that hypothyroidism would be the most common form of TD associated with amiodarone use..$^{5,11,12}$

\section{Materials and methods}

The names of all patients who received amiodarone between November 1999 and December 2002 were obtained from the hospital pharmacy records. Only patients with either cardiac notes or hospital folders were included in the study. Demographic and medical details were extracted from the notes. The medical data included the indication for amiodarone therapy and results of thyroid function tests. TD was categorised by two boardcertified specialist endocrinologists (Table I). The serum samples for $\mathrm{TSH}, \mathrm{fT}_{4}$ and $\mathrm{fT}_{3}$ were measured using the automated chemiluminescence assays manufactured by Bayer Corporation, New York, USA. The interassay coefficient of variation for TSH was $5.48 \%$, for $\mathrm{fT}_{4} 4.6 \%$, and for $\mathrm{fT}_{3} 2.3 \%$. All thyroid function tests were assessed at baseline and at 3 - 6 monthly intervals.

\begin{tabular}{|c|c|c|}
\hline Table I. & $\begin{array}{l}\text { Thyroid diagnoses b } \\
\text { testing }\end{array}$ & by thyroid function \\
\hline \multicolumn{2}{|c|}{ Diagnosis } & Definition \\
\hline \multicolumn{2}{|c|}{ Euthyroidism } & $\begin{array}{l}\mathrm{TSH} 3.5-5.5 \mu \mathrm{IU} / \mathrm{ml} \\
\mathrm{fT}_{4} 11.5-22.7 \mathrm{pmol} / \mathrm{l} \\
\mathrm{fT}_{3} 3.5-6.5 \mathrm{pmol} / \mathrm{l}\end{array}$ \\
\hline \multicolumn{2}{|c|}{ Thyrotoxicosis } & $\begin{array}{l}\mathrm{TSH}<0.01 \mu \mathrm{IU} / \mathrm{ml} \\
\mathrm{fT}_{4}>22.7 \mathrm{pmol} / \mathrm{l} \\
\mathrm{fT}_{3}>6.5 \mathrm{pmol} / 1\end{array}$ \\
\hline \multicolumn{2}{|c|}{ Subclinical hypothyroidism } & $\begin{array}{l}\mathrm{TSH}>5.5 \mu \mathrm{IU} / \mathrm{ml} \\
\mathrm{fT}_{4} 11.5-22.7 \mathrm{pmol} / \mathrm{l} \\
\mathrm{fT}_{3} 3.5-6.5 \mathrm{pmol} / \mathrm{l}\end{array}$ \\
\hline \multicolumn{2}{|c|}{ Hypothyroidism } & $\begin{array}{l}\mathrm{TSH}>5.5 \mu \mathrm{IU} / \mathrm{ml} \\
\mathrm{fT}_{4}<11.5 \mathrm{pmol} / 1 \\
\mathrm{fT}_{3}<3.5 \mathrm{pmol} / \mathrm{l}\end{array}$ \\
\hline \multicolumn{2}{|c|}{ Minor changes in thyroid function } & $\begin{array}{l}\mathrm{TSH}>5.5 \mu \mathrm{IU} / \mathrm{ml} \\
\mathrm{fT}_{4} 11.5-22.7 \mathrm{pmol} / \mathrm{l} \text { or } \\
\mathrm{fT}_{3} \geq 3.5 \mathrm{pmol} / \mathrm{l}\end{array}$ \\
\hline \multicolumn{2}{|c|}{ Subclinicial hyperthyroidism } & $\begin{array}{l}\mathrm{TSH}<0.01 \mu \mathrm{IU} / \mathrm{ml} \\
\mathrm{fT}_{4} 11.5-22.7 \mathrm{pmol} / 1 \\
\mathrm{fT}_{3} 3.5-6.5 \mathrm{pmol} / \mathrm{l}\end{array}$ \\
\hline$f=$ free & & \\
\hline
\end{tabular}

The statistical analyses were performed using Student's $t$ test. All values were expressed using either the mean \pm standard deviation (SD) or median \pm quartile deviation (OD), except when noted. $p$-values $\leq 0.05$ were considered statistically significant.

\section{Results}

One hundred and ninety-four patients received amiodarone during the study period, but the analysis was limited to 163 patients for whom the data were complete. The 31 participants with incomplete data did not differ statistically from the remaining subjects in terms of gender and age, but the median duration of exposure to amiodarone was 219 days in the former versus 1008 days in the cohort with complete data $(p<0.01)$. The study participants were $59 \pm 15$ years of age. There were 67 women and 96 men. TD antedating amiodarone therapy was present in 13 patients (8\%). The indications for amiodarone therapy are shown in Table II.

Table II. Indications for amiodarone therapy

\begin{tabular}{lc|}
\hline Indications & Number of patients (\%) \\
Supraventricular tachycardia & $102(62.2)$ \\
Ventricular tachycardia & $55(33.7)$ \\
Prophylaxis against tachycardia & $3(1.8)$ \\
Uncertain & $3(1.8)$ \\
\hline
\end{tabular}

New-onset TD occurred in 45 patients (27.6\%). Eleven patients $(6.7 \%)$ were thyrotoxic, $1(0.6 \%)$ had transient thyrotoxicosis, 1 (0.6\%) subclinical hyperthyroidism, 13 (8.0\%) had subclinical hypothyroidism, 12 (7.4\%) hypothyroidism and 7 (4.3\%) developed minor changes in thyroid function. Seven of the patients with hypothyroidism and 1 with subclinical hypothyroidism were managed with thyroxine. The cardiologists adopted a protocol whereby they chose to manage hypothyroidism secondary to amiodarone in the following way: if the patients were found to be hypothyroid, the need for amiodarone was reviewed. If an arrhythmia necessitated continued use, thyroxine was added. If amiodarone could be stopped the thyroid function tests were reviewed 3monthly. Thyroxine was introduced if the hypothyroidism persisted beyond 3 months. Subclinical hypothyroid cases were observed for the evolution of hypothyroidism.

Amiodarone was stopped in 6 of the 12 patients with thyrotoxicosis. One patient with subclinical hyperthyroidism was managed with a reduced dose of amiodarone. Therapy for the thyrotoxic patients consisted of amiodarone withdrawal where the cardiovascular status permitted this, radioactive iodine if a sufficient period had elapsed since the withdrawal of amiodarone to permit adequate iodine uptake by the thyroid gland, and neomercazole or prednisone or a combination of both neomercazole and prednisone. The treatment of amiodarone-induced thyrotoxicosis was not uniform as 
different attending physicians offered a variety of expert opinions.

Mortality for the cohort of 163 patients was $12.6 \%$ (confidence interval (CI) 7.9 - 18.8\%). There was no association between mortality and TD $(r=0.04, p>0.8)$. The median duration of amiodarone treatment was 679.0 days (range 3 - 6 425). Three-quarters of the cohort received amiodarone for less than 1172 days. As seen in Table III, the subjects with new-onset thyroid dysfunction had significantly longer duration of amiodarone therapy than those who remained euthyroid $(p=0.05)$. In a lifetable analysis, using a Kaplan-Meier curve, it was shown that the first 1000 days represented the period in which patients were most likely to develop TD. Thereafter the likelihood of developing TD plateaued (Fig. 1).

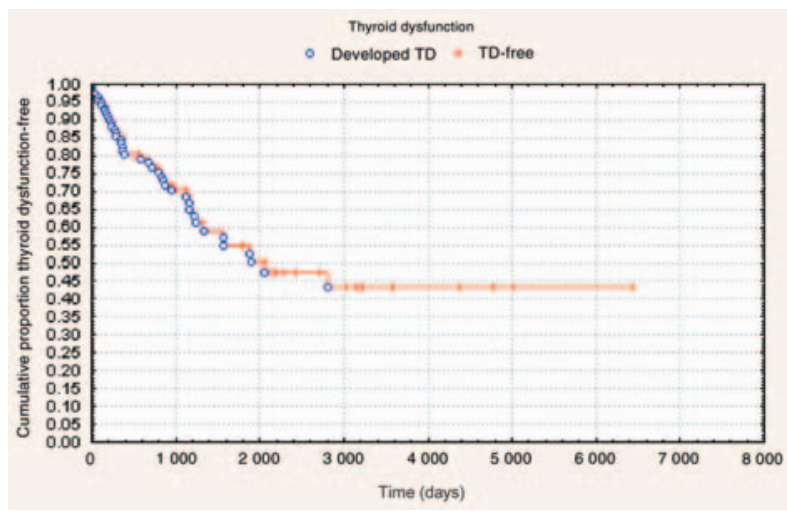

Fig. 1. Kaplan-Meier curve of cumulative risk for development of thyroid dysfunction.

\section{Discussion}

This report represents one of the largest retrospective analyses of TD associated with amiodarone therapy, with a higher frequency of TD demonstrated than in previous studies. ${ }^{13}$ Environmental iodine content has had a major impact on the distribution of the various forms of thyroid dysfunction. Therefore, in other settings in which iodine is replete, hypothyroidism has been the most common abnormality, ranging from $1 \%$ to $32 \% .{ }^{4,11}$ Hypothyroidism was the most common TD in our study, conducted in the iodine-replete Cape Town area, yet it still constituted a much smaller proportion of TD than in previous studies. ${ }^{4,13}$ The reason for this observation is unclear. In many parts of the world TD is not uncommon in people over the age of 60 years. We have previously found that $11.2 \%$ of residents in old-age homes in Cape Town had some degree of TD. ${ }^{14}$ This is similar to the prevalence of TD antedating the initiation of amiodarone therapy in the current cohort. As the patients in this study were not examined for an underlying cause of TD, it was attributed to amiodarone. It is conceivable, however, that new thyroid dysfunction related to amiodarone use may have been overestimated.

\begin{tabular}{|c|c|c|c|}
\hline Table III. & \multicolumn{3}{|c|}{$\begin{array}{l}\text { Clinical characteristics of new-onset thyroid } \\
\text { dysfunction versus euthyroidism in patients } \\
\text { treated with amiodarone }\end{array}$} \\
\hline & & $\begin{array}{l}\text { New thyroid } \\
\text { dysfunction } \\
(\mathbf{N}=45)\end{array}$ & $\begin{array}{l}\text { Euthyroidism } \\
(\mathbf{N}=105)\end{array}$ \\
\hline \multicolumn{4}{|c|}{ Clinical characteristics } \\
\hline \multicolumn{2}{|c|}{ Age (yrs) $($ mean $\pm \mathrm{SD})$} & $60 \pm 15.2$ & $57.7 \pm 15.3$ \\
\hline \multicolumn{2}{|c|}{ Gender (\%) } & Males 66.7 & Males 58.1 \\
\hline \multicolumn{2}{|c|}{$\begin{array}{l}\text { Duration of treatment } \\
\text { (median (OD)) days }\end{array}$} & $943(\mathrm{OD}=1$ 185) & $547(\mathrm{OD}=1135)^{*}$ \\
\hline \multicolumn{4}{|c|}{$\begin{array}{l}\text { Indications for } \\
\text { treatment (\%) }\end{array}$} \\
\hline \multicolumn{3}{|c|}{ Supraventricular } & $68.6+$ \\
\hline \multicolumn{2}{|c|}{ Ventricular tachycardia } & 44 & $28.6+$ \\
\hline \multicolumn{2}{|c|}{ Prophylaxis } & 0.0 & 1.9 \\
\hline \multicolumn{2}{|l|}{ Uncertain } & 4.4 & 1.0 \\
\hline \multicolumn{4}{|l|}{${ }^{*} \mathrm{p}=0.05$} \\
\hline
\end{tabular}

The total thyrotoxicosis prevalence was $7.3 \%$ in our study, compared with previous reports of $1-23 \%{ }^{3,8}$ Amiodaroneinduced thyrotoxicosis prevails in areas with low iodine intake; therefore thyrotoxicosis is more common among Italian than American patients (10\% compared with 2\%), but hypothyroidism is less common (2\% compared with 22\%). ${ }^{4,11}$ Despite the normal environmental iodine exposure in Cape Town, we found a relatively high incidence of hyperthyroidism. It is therefore plausible that a factor other than iodine exposure may be responsible for the wide variation in frequency of TD. In this retrospective study it was not possible to determine whether the thyrotoxicosis in our patients was as a result of type 1 or type 2 amiodarone-induced thyrotoxicosis or a combination of both. These patients were not investigated and managed according to a specific protocol as none was in place in our hospital.

Management of amiodarone-induced thyrotoxicosis is difficult and withdrawal of amiodarone may not be possible, particularly when used for treatment of ventricular arrhythmias. Moreover even if withdrawal is permitted, thyrotoxicosis may take as long as 8 months to subside by virtue of the prolonged half-life of amiodarone. ${ }^{4}$ Amiodarone-induced thyrotoxicosis often responds to antithyroid drugs. Prednisone has proved beneficial in some circumstances, especially in type 2 amiodaroneinduced thyrotoxicosis. ${ }^{4,8}$ Thyroidectomy is reserved for intractable thyrotoxicosis unresposive to medical therapy. However, none of our patients required this intervention. There are a number of options for treating amiodaroneinduced hypothyroidism. These include discontinuing amiodarone therapy, decreasing the dose, or administering replacement therapy with thyroxine. ${ }^{4,5,9}$

Previous life-table analysis has indicated that $49 \%$ of patients receiving amiodarone develop TD by 36 months 
of follow-up. ${ }^{3}$ We have shown that the first 1000 days represents the most likely period in which patients will develop thyroid dysfunction. Nevertheless, the longer an individual is exposed to amiodarone the higher the likelihood of developing TD. This suggests that amiodarone-induced TD is the result of prolonged exposure, warranting continued surveillance of thyroid function in patients on amiodarone therapy.

Our study has some limitations. Although it represents one of the largest data collections, the analysis was restricted to 163 patients (84\% of the total) with complete data. Demographic characteristics of the 31 patients excluded from data analysis did not differ from those of the remaining patients. However those with incomplete data had a shorter exposure to amiodarone, possibly because of the omission of thyroid function testing in patients given a short course of therapy. This may have introduced a degree of bias. In common with other retrospective analyses, clinical data were often deficient and therefore the clinical assessment of goitre size and testing for thyroid antibodies were not performed routinely. We suggest that the following be undertaken before initiating amiodarone therapy: clinical examination of the thyroid gland and examination for features of Graves' disease, and exclusion of thyroid-associated ophthalmopathy. Thyroid function tests and thyroid antibody screening should be requested at baseline. This will help to identify patients at increased risk of TD. Measurements of $\mathrm{TSH}_{1} \mathrm{fT}_{4}$ and $\mathrm{fT}_{3}$ should therefore be reassessed 3 months after commencing amioadarone. Thereafter TSH should be checked every 4 - 6 months. An elevated TSH, together with a low $\mathrm{fT}_{4}$, indicates hypothyroidism and necessitates treatment with thyroxine. An abnormally low TSH, or a drop in TSH, requires assessment of $\mathrm{fT}_{3}$ and $\mathrm{fT}_{4}$. A suppressed TSH with both an elevated $\mathrm{fT}_{4}$ and $\mathrm{fT}_{3}$ confirms hyperthyroidism and necessitates investigation and treatment. ${ }^{4}$

\section{Conclusion}

In conclusion, we found an overall high incidence of amiodarone-induced TD in the Western Cape. Local and environmental factors that may explain this high incidence require investigation. Ideally amiodaroneinduced TD should be managed jointly by endocrinologists and cardiologists using an evidencebased protocol.

1. Rosenbaum MB, Chiale PA, Halpern MS, et al. Clinical efficacy of amiodarone as an antiarrhythmic agent. Am J Cardiol 1976; 38: 934-944.

2. Fradkin JE, Wolff J. Iodine induced thyrotoxicosis. Medicine 1983; 62: 1-20.

3. Albert SG, Alves LE, Rose EP. Thyroid dysfunction during chronic amiodarone therapy. $J$ Am Coll Cardiol 1987; 9: 175-183.

4. Harjai KJ, Licata AA. Effects of amiodarone on thyroid function. Ann Intern Med 1997; 126: $63-73$.

5. Martino E, Aghini-Lombardi F, Mariotti S, et al. Amiodarone iodine-induced hypothyroidism: risk factors and follow up in 28 cases. Clin Endocrinol (Oxf) 1987; 26: 227-237.

6. Figge HL, Figge J. The effects of amiodarone on thyroid hormone function: a review of physiology and clinical manifestations. J Clin Pharmacol 1990; 30: 588-595.

7. Ingbar SH. Autoregulation of the thyroid. Mayo Clin Proc 1972; 47: 814-823.

8. Bartalena L, Brognioni S, Grasso L, Bogazzi F, Burelli A, Martino E. Treatment of amiodarone induced thyrotoxicosis, a difficult challenge: results of a retrospective study. J Clin Endocrinol Metab 1996; 81: 2930-2933.

9. Klein I, Ojamaa K. Thyroid hormone and the cardiovascular system. N Engl J Med 2001; 344: 501-509

10. Burger A, Dinichert D, Nicod P, Jenny M, Lemarchand-Beraud T, Vallotton MB. Effect of amiodarone on serum triiodothyronine, reverse triiodothyronine, thyroxin, and thyrotropin. A drug influencing peripheral metabolism of thyroid hormones. J Clin Invest 1976; 58: 255-259.

11. Immelman R, Towindo $\mathrm{T}$, Paiker J, et al. Report of the South African Institute for Medical Research on the iodine deficiency disorder survey of primary school learners for the department of health, South Africa. Pretoria: Department of Health/SAIMR, 2000.

12. Martino E, Safran M, Aghini-Lombardi F, et al. Environmental iodine intake and thyroid dysfunction during chronic amiodarone therapy. Ann Intern Med 1984; 101: 28-34.

13. Sanmarti A, Permanyer-Miralda G, Castellanos JM, Fos-Sala M, Galard RM, Soler-Soler J. Chronic administration of amiodarone and thyroid function: A follow-up study. Am Heart J 1984: 108: 1262-1268.

14. Muller GM, Levitt NS, Louw SJ. Thyroid dysfunction in the elderly. S Afr Med J 1997; 87: $1119-1123$.

Reprinted from the South African Medical Journal (2005; 95: 180-183). 